\title{
The role of the university in achieving SDGs 4 and 7: a Ukrainian case
}

\author{
Artem Artyukhov ${ }^{1}$, Iurii Volk ${ }^{2}$, Tetyana Vasylieva ${ }^{3}$, and Serhiy Lyeonov ${ }^{4}$ \\ ${ }^{1}$ Department of Marketing, Institute for Business, Economics and Management, Sumy State University, \\ Rymskogo-Korsakova str. 2, 40007 Sumy, Ukraine \\ ${ }^{2}$ Department of Applied Mathematics and Complex Systems Modeling, Faculty of Electronics and \\ Information Technologies, Sumy State University, Rymskogo-Korsakova str. 2, 40007 Sumy, Ukraine \\ ${ }^{3}$ Academic and Scientific Institute of Business, Economics and Management, Sumy State University, \\ Rymskogo-Korsakova str. 2, 40007 Sumy, Ukraine \\ ${ }^{4}$ Office of the First Vice-rector of Sumy State University, 2, Rymskogo-Korsakova str. 2, 40007 Sumy, \\ Ukraine
}

\begin{abstract}
This article deals with the development of the university activities model to ensure the quality of education and technology transfer (SDG 4) and to create a successful background in achieving SDG 7. We conduct an analysis of the literature on the achievement of SDGs through governmental instruments of influence, as well as the creation of effective university model ensuring the education quality and technology transfer. In addition, we demonstrate the role of the government in financing higher education in Ukraine. We also present the evaluation of the popularity of educational programs related to energy efficiency and a "clean" environment in Ukrainian universities after the adoption of the 2030 Agenda for Sustainable Development. The indicators of the use of various energy types by Ukraine are assessed, and a comparative analysis of these indicators with the data for EU-28 is performed. Based on the data presented, conclusions are drawn about the need to improve the quality of university training and to activate the university technology transfer. Successful practical approaches that can be of use for different higher education institutions are outlined. A combined model of quality assurance and technology transfer at the university is presented. An algorithm for testing the model and assessing the technological level of readiness for implementation is developed. The presented chain "combined model - model testing algorithm - determination of the technological level of readiness" is also assessed from the point of view of socio-economic impact on the main stakeholders. The use of the combined model lays background for the university's own sustainable development as a tool for achieving SDGs.
\end{abstract}

\section{Introduction}

The focus from United Nations Millennium Development Goal 7 "Ensure environmental sustainability" was shifted in 2015 towards Sustainable Development Goals 7 "Affordable and clean energy" and 12 "Sustainable consumption and production" stated by the 2030 Agenda for Sustainable Development. Expansion and detailing of sustainable development 
goals indicates both the emergence of new global problems and the fact that the certain tasks of The Millennium Development Goals have not been resolved. This is evidenced by the active discussion of "clean" ("green") energy problems and measures to increase energy efficiency. The International Energy Agency stated that COVID-19 outbreak tends to wipe out demand for fossil fuels, causing a market crash seven times greater than that seen during the global financial crisis. "The most severe plunge in energy demand since the second world war would trigger multi-decade lows for the world's consumption of oil, gas and coal while renewable energy continued to grow. The steady rise of renewable energy combined with the collapse in demand for fossil fuels means clean electricity will play its largest ever role in the global energy system this year, and help erase a decade's growth of global carbon emissions" [2].

The International Energy Agency also analyzes [3] the role of energy efficiency in improving government stimulus packages during the COVID-19 crisis. The meeting held on $21^{\text {st }}$ of April 2020 covered the topic of securing long-term improvements in energy systems, the potential for energy efficiency to create jobs and to accelerate economic growth. The Global Commission for Urgent Action on Energy Efficiency provided recommendations for governments on how they can effectively accelerate energy efficiency through policy action.

Sustainable Development Goal 4 "Quality Education" is another sustainable development goal formulated by the 2030 Agenda for Sustainable Development, which authors believe to be decisive in the formation of energy efficient and "clean" global landscape. It allows creating the basis for the formation of responsible energy consumption culture and advocates the search for new energy sources. In addition, the specified Sustainable Development Goal should ensure a successful transfer of knowledge and technology to the real economy sector.

Working to achieve SDGs requires each country to independently develop its own sustainable development strategies, plans and programs. Such programs should be developed in centers of concentrated scientific knowledge, which are universities. Designing the sustainable development plans is impossible without the participation of industry representatives acting as the main university partners. In addition, the program development process has to include consideration of the views of other stakeholders, such as alumni.

\section{Literature review}

We should mention a number of scientific studies that focus on the university role in achieving SDGs. Paper [4] proposes a comprehensive management model for a sustainable university consisting of four strategic management process stages. The model is derived relying on data from a number of American (both continents), European, Asian and Pacific universities. In terms of strategies for fostering sustainability, namely education and research, this model requires clarification taking into account the peculiarities of the functioning universities in Eastern Europe and former USSR countries.

A separate role is assigned to the opinion of students during the modeling of university as a center for sustainable development [5]. The survey of these stakeholders in [5] was focused only on the public liberal arts (where technology transfer is not a priority in the university activities) and was devoted to the description of source and message channels for receiving sustainability information, and not to the study of mechanisms for ensuring education quality and technology transfer. Another attempt to carry out the survey the student perception of SDGs in both professional and personal way was made in [6]. Based on the analysis carried out in the paper, authors derived practical implications intended to battle student ignorance regarding SDGs. However, the detailed plan and means to establish comprehensive quality educational system were out of discussion. Works $[7,8]$ provide a general overview of the methods used to implement the concept of a "sustainable university", including communication with external stakeholders. 
A multi-country study identifying the level of importance given to desired competences on sustainable development by teaching staff at a number of higher education institutions was presented in [9]. Despite some limitations, authors outlined practical recommendations for teaching practices regarding sustainable development.

The relationship "university - SDG 7" is of particular interest. The existence of such a relationship is clearly defined by "THE Impact Rankings 2020 by SDG: affordable and clean energy (SDG 7) methodology" [10]. In particular, mentioned Rankings define the following indicators: "Plan to reduce overall energy consumption" and "Reviews to identify areas where energy waste is highest". These indicators stimulate the university to conduct the technology transfer from science to production and to use its own developments within the university. The Systematic Literature Review on this issue was carried out in [11] with the definition of the main accents (directions) in the university activities to comply with SDG 7 targets in their functioning and in the creation of new products for industry.

The national cases, e.g. Spanish [12] are particularly informative from the point of view of adaptation for Ukrainian universities. In [13] authors develop a process framework for including education for sustainable development into quality management systems in higher education. This work represents a valuable example of sustainability implementation in higher education in form of quality assurance systems on managerial level to secure and improve teaching and learning. However, it focuses on a limited subset of 11 universities in Nordic countries leaving the room for development of frameworks aimed to address SDG 4 tasks in other countries.

We should also note research works in various applications related to sustainable development and quality of education: financing of educational activities [14]; innovative potential of the national economy [15]; state regulation of educational processes as a tool for sustainable development [16-18]; the development of various educational areas in the regions [19-26]; lifelong learning and its impact on the development of the region [27], some financial issues and risks in particular for Africa and India [28-31]. The presented studies are of practical interest for building the model of the university activities, taking into account regional characteristics and mechanisms for describing individual elements in the quality education system.

Separately, it is necessary to highlight a selection of articles that are devoted to innovation as an integral attribute of sustainable development. So, in [32], special attention is paid to innovative tools for achieving high ratings. The works $[33,34]$ describe the relationship between education, science and innovation and offer mechanisms for optimizing the algorithms for the operation of these systems.

It should be noted that the effective implementation of the main tasks of the university activities is possible only under stable and sufficient funding. Despite the fact that in absolute terms the share of higher education funding in Ukraine is one of the lowest in Europe, this indicator is very high in percentage terms as shown in Table 1. This fact gives hope for the prospect of "strengthening" universities in terms of ensuring the higher education quality and successful technology transfer.

Current paper represents an attempt to describe the university activities in terms of higher education quality assurance and technology transfer in application to achieve the main results of SDGs 4 and 7.

It should be noted that SDG 4 is one of the leaders by mention frequency (third place) [36] in five main reports on sustainable development goals in 2019 [37-40]. Therefore, the relevance of the problem of the achievement of other SDGs through the successful overcoming of the main challenges of SDG 4 presented in this paper is confirmed. 
Table 1. Expenditures on higher education (by budget expenditures as a percentage of

\begin{tabular}{|l|c|c|c|c|c|}
\hline Gountry & $\mathbf{2 0 1 3}$ & $\mathbf{2 0 1 4}$ & $\mathbf{2 0 1 5}$ & $\mathbf{2 0 1 6}$ & $\mathbf{2 0 1 7}$ \\
\hline USA & 1.34 & 1.36 & 1.37 & 1.21 & - \\
\hline United Kingdom & 1.34 & 1.38 & 1.28 & 1.41 & - \\
\hline Germany & 1.31 & 1.31 & 1.25 & 1.25 & - \\
\hline France & 1.24 & 1.25 & 1.25 & 1.23 & - \\
\hline Poland & 1.21 & 1.18 & 1.22 & 1.06 & - \\
\hline $\begin{array}{l}\text { Republic of } \\
\text { Belarus }\end{array}$ & 0.88 & 0.81 & 0.80 & 0.80 & 0.79 \\
\hline Georgia & - & - & - & 0.42 & 0.39 \\
\hline Ukraine & 2.13 & 1.85 & - & 1.53 & 1.35 \\
\hline
\end{tabular}

Achievement of the stated goal is possible through the following tasks solution:

1. Data analysis on the training of specialists in fields of energy management and production, energy efficiency, ecology, environmental protection technology.

2. Development of a set of measures to improve the quality of education in order to train graduates competitive in the labor market.

3. Analysis of the functioning university technology transfer centers activity and their role in ensuring a successful relationship between science and industry.

4. Development and selection of an algorithm for testing the functioning model of the university as a training center for specialists in fields of ecology, energy efficiency and "clean" energy and as a coordinator of technology transfer in these areas.

The proposed model of the university activity is based on the regulatory framework, algorithms and mechanisms for the functioning of the education ensuring system and technology transfer in Sumy State University. Authors' choice of the base university for the model description was motivated by following factors:

1. The presence of the university in established international rankings [41-43].

2. Confirmation of the higher education quality system effectiveness based on external assessment according to the National Agency for Higher Education Quality Assurance (Ukraine) (https://en.naqa.gov.ua).

3. The efficiency of technology transfer implementation through the commercialization of scientific developments and financial indicators of technology transfer according to the Ministry of Education and Science of Ukraine (https://mon.gov.ua).

4. Active presence of projects in the field of energy efficiency and "clean" energy.

5. Implementation of energy efficiency ensuring instruments in its own activities.

The combination of high rating indicators with the effective implementation of technology transfer provides the prerequisites for the development of a successful model of the university's activities and the implementation of the targets set within the SDG 7 [44]:

“7.1 By 2030, ensure universal access to affordable, reliable and modern energy services.

7.2 By 2030, increase substantially the share of renewable energy in the global energy mix.

7.3 By 2030, double the global rate of improvement in energy efficiency.

7.A By 2030, enhance international cooperation to facilitate access to clean energy research and technology, including renewable energy, energy efficiency and advanced and cleaner fossil-fuel technology, and promote investment in energy infrastructure and clean energy technology". 


\section{Research methodology, results and discussion}

\subsection{Educational programs popularity assessment}

Principal task of data analysis on the training of specialists in fields of energy management and production, energy efficiency, ecology, environmental protection technology is addressed by the use of open datasets provided by Ministry of Education and Science of Ukraine on the Open Data Portal (data.gov.ua). To monitor the actual state of affairs regarding training of relevant field specialists' authors analyzed the dataset containing full information on admissions to the higher education institutions since 2012 to 2021 licensed under Creative Commons Attribution 4.0 International license. The scope of analysis was reduced to admission of fulltime bachelor, masters and $\mathrm{PhD}$ level entrants on the governmental and commercial funding basis since 2016 (explained by emerging of SDGs in late 2015).

The dynamics of specialties "Ecology" and "Environmental protection technology" admission percentage to total number of government-funded and commercial entrants per year (2016 to 2020) is represented by Figure 1A. Line 1 represents the dynamics of fulltime admissions on governmental funding basis, Line 2 - fulltime commercial admissions. The peak percentage values appear to be small relatively to the highly popular specialties like "Computer Sciences" ( $\sim 8 \%$ of government funded admissions in 2020$)$ or "Law" ( $4 \%$ of government funded admissions in 2020). However, one can clearly witness that the number of governments funded entrants to "Ecology" and "Environmental protection technology" tends to grow from year to year indicating increasing interest in mentioned specialties. As for commercial entrants, Line 2 indicates stable number of fulltime commercial admissions to the specialties under consideration. Further application of governmental support (e.g. increasing number of available funded places) on mentioned fields of education may result in significant impact on fulfilling SDG 4 principles by forming a highly trained specialist community motivated to address environmental problems.

Figure 1B displays dynamics of specialties "Electroenergetics, electrotechnics and electromechanics", "Energetic engineering", "Atomic Energetics", "Heat Energetics", "Hydroenergetics" admission percentage to total number of government-funded and commercial entrants per year (2016 to 2020). Line 1 represents fulltime entrants on governmental funding basis, Line 2 - fulltime entrants on commercial basis. We can see stable interest of entrants in the mentioned specialties in both government funded and commercial types of admission. By increasing attention to the "green" energy concepts, alternative energy sources and efficient environmental resource management in the educational programs of the mentioned specialties universities can ensure orientation of graduating specialists towards SDG 7 achievement.

Figure 1C represents the dynamics of specialties "Ecology" and "Environmental protection technology" admission percentage of total entrant number on the master and $\mathrm{PhD}$ level. As Line 1 illustrates, percent of government-funded entrants on higher education level of mentioned specialties tend to decrease. Line 2 presenting commercial base entrants dynamics express the same tendency, however having the peak admission number in 2019 (753 commercial entrants vs. 725 government-funded entrants). The reasons for this peak admission numbers and possible outcomes for the aspects of scientific community development and technology transfer require further study. 

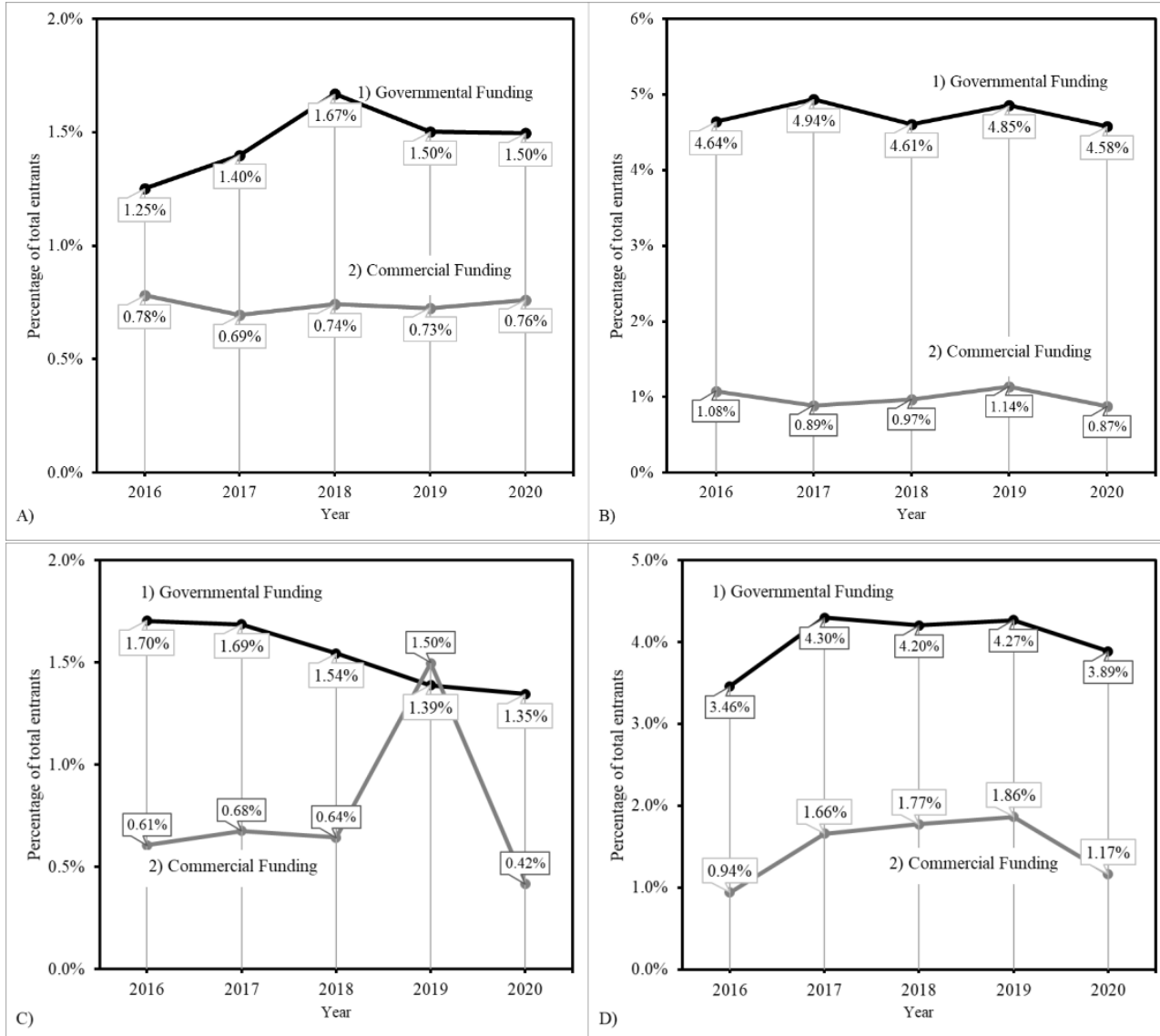

Fig. 1. Dynamics of admission percentage on SDG 7 related specialties per year

Figure 1D illustrates the dynamics "Electroenergetics, electrotechnics and electromechanics", "Energetic engineering", "Atomic Energetics", "Heat Energetics", "Hydroenergetics" admission percentage to total number of government-funded and commercial entrants per year (2016 to 2020) on the master and PhD level. Line 1 represents positions with governmental funding, Line 2 - commercial entrants. The overall character of the dynamics expresses relatively stable interest of entrants to the specialties related to energy production. Therefore, the changes to educational programs addressing tasks of SDG 7 are necessary in order to ensure energy efficient society. Master and $\mathrm{PhD}$ level program revisions and quality assurance are of extreme importance since graduates of these educational levels have the major impact on the formation of the comprehensive landscape of sustainable development in higher education, technology transfer and "green" energy concepts.

\subsection{Indicators of various energy types use by Ukraine assessment}

In order to understand the current situation regarding SDGs 4 and 7 achievement courses in Ukraine, we assess statistical data about electrical energy production in Ukraine and EU28 provided by International Energy Agency. Using table data available at [45] in Figure 2 we present dynamics of energy production percentage by source for 2015-2019-time interval. Nuclear power plants, coal-based electricity generation, hydroelectricity and solar 
energy produced by photovoltaic systems were considered. As shown in Figure 2A, a major part ( $49-55 \%)$ of electrical energy in Ukraine is nuclear-produced and this fact tend to stay stable throughout studied time. On the other hand, nuclear energy possesses only $\sim 25-26 \%$ share of EU-28 energy production landscape. Authors' opinion is that ongoing process of nuclear power phase-out in EU countries is an integral part of the SDG 7 achievement and this practice should be inherited in Ukraine.
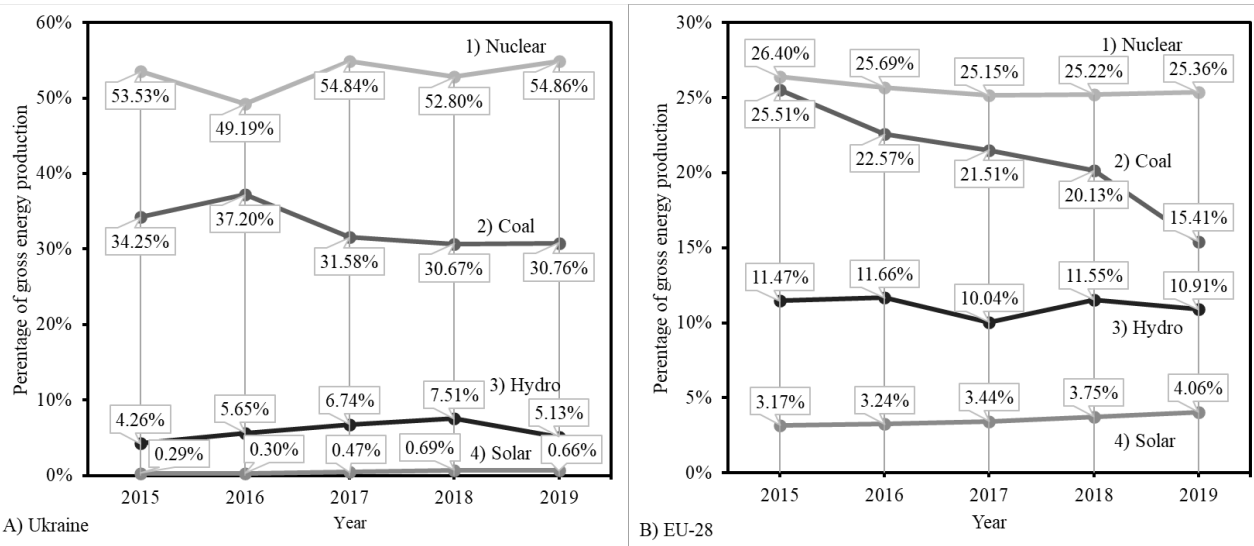

Fig. 2. Electrical energy production percentage by source in Ukraine and EU-28

A significant decrease in coal-based electrical energy production in EU-28 countries is evidenced by the dynamics of Line 2 in Figure 2B. The percentage of energy produced by coal burning decreased from $25.5 \%$ to $15.4 \%$ in European Union countries, while in Ukraine this indicator stays around $30 \%$ for years under study.

Both Ukraine and EU-28 countries express stable dynamics in hydroelectricity production. However, the share of this energy source in Ukraine does not exceed $7 \%$, while in European countries $\sim 11 \%$ of energy is produced by hydroelectric power plants.

The situation with solar energy raises concerns regarding SDG 7 achievement in Ukraine. The share of the electrical energy produced by solar photovoltaic process in Ukraine does not exceed 1\%, while EU-28 countries express stable (yet not rapid) growth of interest to the solar energy sources by raising production share from 3\% in 2015 to $4 \%$ in 2019 .

As mentioned in introduction, SDG 7 comprises five key targets aimed to ensure energy efficiency concepts. Target 7.2 dealing with substantial increase the share of renewable energy in the global energy mix is at the most interest in context of current paper. As shown by analytics, the course of Ukrainian energetics stays unchanged neglecting the development and usage of energy efficiency technologies. This may be explained by various reasons, including the lack of highly trained specialists in fields of environmental protection and ecological studies. Therefore, the role of university as a platform interconnecting quality education, research sector and industry representatives emerges in a bright light.

Successful cases of scientific developments introduction in the field of energy efficiency [48-50] and environmentally friendly devices [51, 52] at domestic chemical enterprises make it possible to consider the proposed transfer model effective.

University scientists have created a number of projects that allow solving the problems of SDG 7 targets achievement both in industry and for their own needs.

The results of testing the algorithm along the chain "testing - quality control - internal quality assurance - external quality assurance" allow consistent fulfilling of the conditions for the model successful operation thus minimizing the number of testing cycles. In order to 
optimize verification process, it is necessary to create a detailed technical task and this role is assigned to the university regulatory framework.

Table 2. Projects aimed at SDG 7 achievement in industry and at the university (according to [53])

\begin{tabular}{|c|c|}
\hline Title & Short description \\
\hline $\begin{array}{l}\text { Jet thermal } \\
\text { transformer for } \\
\text { municipal and } \\
\text { industrial } \\
\text { households heating } \\
\text { and cooling } \\
\text { systems }\end{array}$ & $\begin{array}{l}\text { The combination of direct and reversible cycles with the implementation of } \\
\text { the principle of jet thermal compression will allow to achieve higher } \\
\text { transformation coefficients in lowering thermal transformer. } \\
\text { Heat sources modernization is possible by decommissioning of } 60-70 \% \\
\text { unprofitable boilers and the retrofitting of other boilers by jet thermal } \\
\text { transformer blocks (working boilers are used as working fluid heaters). }\end{array}$ \\
\hline $\begin{array}{l}\text { Expansion turbine } \\
\text { (ET) - an electric } \\
\text { power generation } \\
\text { unit as a part of jet- } \\
\text { reactive (JRT) and } \\
\text { vortex turbines }\end{array}$ & $\begin{array}{l}\text { JRT transforms the potential energy of compressed gas into kinetic jet energy } \\
\text { which flows from a tractive nozzle and is at some distance from the rotation } \\
\text { axis. Existing world analogues are characterized by relatively high capital } \\
\text { costs that do not provide the minimum acceptable payback period. The } \\
\text { advantages of JRT enable to develop the ET with the payback period of } 1-2 \\
\text { years. It is cheaper, of simple technology and design, safe and easy to use as } \\
\text { compared to the ET on the basis of the conventional paddle turbines. }\end{array}$ \\
\hline $\begin{array}{l}\text { Turbogenerators } \\
\text { based on vortex } \\
\text { turbines }\end{array}$ & $\begin{array}{l}\text { The vortex turbine is structurally and technologically simple, cheap to } \\
\text { manufacture and has a nominal operating mode at lower speeds than } \\
\text { conventional (centripetal and axial) turbines. The last advantage of the vortex } \\
\text { turbines makes it possible to create turbine generators in gearless design with } \\
\text { a capacity of up to } 500 \mathrm{~kW} \text { and a payback period of } 1-2 \text { years. }\end{array}$ \\
\hline $\begin{array}{l}\text { Monitoring system } \\
\text { "HeatCAM" }\end{array}$ & $\begin{array}{l}\text { Monitoring system «HeatCAM» provides: monitoring of the performance of } \\
\text { the heating network based on weather; computation of the amount of heat } \\
\text { energy; formation of accounting documentation. Application of the system } \\
\text { during monitoring of heat supply allows reducing the amount of heat energy } \\
\text { consumption up to } 15 \% \text {. }\end{array}$ \\
\hline $\begin{array}{l}\text { Monitoring system } \\
\text { "Energy clock" }\end{array}$ & $\begin{array}{l}\text { The "Energy clock" device installed on the water distribution unit is the main } \\
\text { component of the demonstration site that allows real-time demonstration of } \\
\text { the amount of water used and its cost to the consumer. The "Energy clock" } \\
\text { system reduces the heat energy consumption by } 15 \% \text {. }\end{array}$ \\
\hline $\begin{array}{l}\text { 3rd generation N- } \\
\text { CDS/P-SNS } \\
\text { heterorocotion- } \\
\text { based solar cells }\end{array}$ & $\begin{array}{l}\text { The main advantage of the device is minimal content of heavy metal } \\
\text { (cadmium) due to the use of tin sulfide as an absorbent material. SnS is a } \\
\text { cheap non-toxic material, which reduces the cost of the device and simplifies } \\
\text { the disposal after the expiration date. }\end{array}$ \\
\hline $\begin{array}{l}\text { Heat-generating } \\
\text { unit }\end{array}$ & $\begin{array}{l}\text { The warming of the liquid is carried out by forces of viscous friction, which } \\
\text { eliminates the use of heating elements. Cost reduction of heating is } 40-60 \% \text {. }\end{array}$ \\
\hline
\end{tabular}

After successfully testing the model and receiving feedback from the main stakeholders, it is possible to assess the level of technological readiness of the model for large-scale implementation and replication to other SDGs.

\section{Conclusions}

All in all, our analysis of literature data showed that there is an urgent need to use effective solutions for organizing activities in achieving the SDGs. The solution of combining "quality of education" and "transfer of technologies" into a joint model is a new approach to a comprehensive solution to the problem of managing the educational and scientific potential of the university. The presented chain "combined model - model testing algorithm determination of the technological level of readiness" is also assessed from the point of view 
of socio-economic impact on the main stakeholders. The use of the combined model allows for the university's own sustainable development as a tool for achieving SDGs.

The assessment made about current state of affairs regarding SDG 4 and 7 related specialties admission dynamics mark the possible routes for improvement in educational plans covering competences of environmental influence. Considering these results during the combined model development and testing may result in level of effort optimization at stages related with SDG 4 achieving and hence, other linked model elements.

At each stage of modeling and testing the system, it is possible to eliminate systemic errors in the organization of interaction between the educational and scientific spheres. This approach allows achieving of high technological level of readiness for the model implementation within a relatively short testing time. The proposed model can also be adapted to achieve other sustainable development goals. By replacing (modernizing) individual blocks of the model, flexibility is achieved in ensuring interconnection in the chain "SDG 4 - other SDGs". The proposed analogy between testing a university activity model and software product testing effectively operates in the system "quality of education technology transfer - achievement of SDGs". Despite limitations dictated by single university case consideration, paper provides a set of timely practical approaches that may be successfully deployed to other Ukrainian universities.

\section{Acknowledgments}

This research was funded by the grants from the Ministry of Education and Science of Ukraine "Reforming the lifelong learning system in Ukraine for the prevention of the labor emigration: a coopetition model of institutional partnership" (reg. No 0120U102001), "Convergence of economic and educational transformations in the digital society: modeling the impact on regional and national security".

\section{References}

1. The impact of the Covid-19 crisis on clean energy progress, https://www.iea.org/articles/the-impact-of-the-covid-19-crisis-on-clean-energyprogress (2020)

2. Covid-19 crisis will wipe out demand for fossil fuels, says IEA, https://www.theguardian.com/business/2020/apr/30/covid-19-crisis-demandfossil-fuels-iea-renewable-electricity (2020)

3. IEA brings together leading global figures to discuss the role of energy efficiency in Covid-19 stimulus packages, https://www.iea.org/news/iea-brings-togetherleading-global-figures-to-discuss-the-role-of-energy-efficiency-in-covid-19stimulus-packages (2020)

4. L. Velazquez, N. Munguia, A. Platt, J. Taddei, Journal of Cleaner Production, 14(911), 810 (2006)

5. E. K. Perrault, S. K. Clark, Journal of Geoscience Education, 65(2), 194 (2017)

6. F. Zamora-Polo, J. Sánchez-Martín, M. Corrales-Serrano, L. Espejo-Antúnez, Sustainability, (11), 3533 (2019)

7. L.P. Amaral, N. Martins, J.B. Gouveia, International Journal of Sustainability in Higher Education, 16(2), 155 (2015)

8. S. Mosier, M Ruxton, Environment and Planning C: Politics and Space, 36(3), 479 (2018)

9. W. Leal Filho, V.R. Levesque, A.L Salvia, et al., Sustainability Science 16, 101 (2021) 
10. THE Impact Rankings 2020 by SDG: affordable and clean energy (SDG 7) methodology, https://www.timeshighereducation.com/impact-rankings-2020-sdgaffordable-and-clean-energy-sdg-7-methodology (2020)

11. A. L. Salvia, L. L. Brandli, Energy Sustainability at Universities and Its Contribution to SDG 7: A Systematic Literature Review, (2020)

12. N. Blasco, I. Brusca, M. Labrador, Sustainability 13, 89 (2021)

13. T. Holm, K. Sammalisto, T. S. Grindsted, T. Vuorisalo, Journal of Cleaner Production 106, 164 (2015)

14. S. Lyeonov, O. Liuta, Actual problems of finance teaching in Ukraine in the postcrisis period (2016)

15. T. A. Vasylieva, V.O Kasyanenko, Actual Problems of Economics, 144(6), 50 (2013)

16. A. Vorontsova, T. Vasylieva, Y. Bilan, G. Ostasz, T. Mayboroda, Administratie Si Management Public, 2020(34), 6 (2020)

17. Y. Bilan, T. Pimonenko, L. Starchenko, E3S Web of Conferences 159, 04037 (2020)

18. A. Vorontsova, H. Shvindina, T. Mayboroda, H. Mishenina, I, Heiets, Problems and Perspectives in Management, 18(4), 275-288 (2020)

19. A. R. V. Yapo, SocioEconomic Challenges, 3(3), 108 (2019)

20. K. S. Akpoviroro, P.M Akanmu, A. Olalekan, S. A. Alhaji, SocioEconomic Challenges, 4(2), 114 (2018)

21. F.F. Sapele, S.A. Idoniboye-Obu, Business Ethics and Leadership, 3(3), 78-87 (2019)

22. B.A. Brimah, W.D. Olanipekun, A.G. Bamidele, M. Ibrahim, Financial Markets, Institutions and Risks, 4(2), 34 (2020)

23. M.S. Ayad, A.A. El-Aziz, SocioEconomic Challenges, 2(2), 49 (2018)

24. I. Skliar, Business Ethics and Leadership, 2(1), 96 (2018)

25. N. Vardanyan, Business Ethics and Leadership, 1(3), 93 (2017)

26. M. Mazurkiewicz, O. Liuta, K. Kyrychenko, Business Ethics and Leadership, 1(4), 74 (2017)

27. S. Pryima, Y. Dayong, O. Anishenko, Y. Petrushenko, A. Vorontsova, Problems and Perspectives in Management, 16(3), 1-13 (2018)

28. P.M. Akanmu, J.Ol. Clement, M. Samaila, Financial Markets, Institutions and Risks, 2(4), 20 (2018)

29. H. Hadbaa, R. Boutti, Financial Markets, Institutions and Risks, 3(1), 92 (2019)

30. Al.K. Chakrawal, P. Goyal, Financial Markets, Institutions and Risks, 2(3), 28 (2018)

31. T. Bachoo, N.S.M. Ahmad, Financial Markets, Institutions and Risks, 2(4), 101 (2018)

32. S. Kvitka, G. Starushenko, V. Koval, H. Deforzh, O. Prokopenko, Marketing and Management of Innovations, 3, 60 (2019)

33. S. Shkarlet, N. Kholiavko, M. Dubyna, Marketing and Management of Innovations, 3, $126(2019)$

34. A.S. Vorontsova, S.V. Lieonov, T. A.Vasylieva, A.Y. Artiukhov, Marketing and Management of Innovations, 2, 218 (2018)

35. Annual report of National Agency for Quality Assurance in Higher Education of Ukraine: 2019, https://naqa.gov.ua/wp-content/uploads/2020/02/3вim-2020.pdf (2020)

36. World's five major SDG reports, Basel Institute of Commons and Economics, http://commons.ch/wp-

content/uploads/Synopsis_SDG_Reports_Goals_Allocation_2019.pdf(2019) 
37. The Sustainable Development Goals report 2019, https://unstats.un.org/sdgs/report/2019/The-Sustainable-Development-GoalsReport-2019.pdf(2019)

38. Inter-agency Task Force on Financing for Development: Financing for Sustainable Development Report 2019, https://developmentfinance.un.org/sites/developmentfinance.un.org/files/FS DR2019.pdf (2019)

39. General, Global Sustainable Development Report 2019: The Future is Now Science for Achieving Sustainable Development, https://sustainabledevelopment.un.org/content/documents/24797GS DR_report_2019.pdf(2019)

40. Sustainable development in the European Union, https://ec.europa.eu/eurostat/documents/3217494/9940483/KS-02-19-165-ENN.pdf (2019)

41. Ranking WEB of Universities, http://webometrics.info/en (2021)

42. THE World University Rankings, https://www.timeshighereducation.com/worlduniversity-rankings (2021)

43. QS World University Rankings, https://www.topuniversities.com/universityrankings/world-university-rankings/2021 (2021)

44. Sustainable Development Goal 7: Ensure access to affordable, reliable, sustainable and modern energy for all, https://sdgs.un.org/ru/goals/goal7 (2021)

45. Data Tables - Data \& Statistics, IEA, https://www.iea.org/data-and-statistics/datatables (2021)

46. Sustainable Development Goal 4: Ensure inclusive and equitable quality education and promote lifelong learning opportunities for all, https://sdgs.un.org/ru/goals/goal4 (2021)

47. E. Unterhalter, Global Policy, 10, 39-51 (2019)

48. A. Artyukhov, N. Artyukhova, J. Krmela, V. Krmelová, IOP Conference Series: Materials Science and Engineering, 776(1), 012018 (2020).

49. A. Artyukhov, N. Artyukhova, J. Krmela, V. Krmelová, IOP Conference Series: Materials Science and Engineering, 776(1), 012016 (2020)

50. A. Artyukhov, N. Artyukhova, A. Ivaniia, TCSET 2018 - Proceedings, 139 - 142 (2018)

51. A. Artyukhov, V. Obodiak, P. Boiko, P. Rossi, CEUR Workshop Proceedings, 1844, $33-47$ (2017)

52. V. Obodiak, N. Artyukhova, A. Artyukhov, Calculation of the residence time of dispersed phase in sectioned devices: Theoretical basics and software implementation, 813-820 (In Advances in Design, Simulation and Manufacturing II. DSMIE 2019. Lecture Notes in Mechanical Engineering. Springer, Cham: 2020)

53. Information resource of innovative developments, https://innovation.sumdu.edu.ua/?lang=en (2021) 